\title{
Lived experiences of nurses as family caregivers in advanced cancer
}

\section{by Lisa Cicchelli and Deborah McLeod}

It is an honour to have received the 2011 Helene Hudson Lectureship award. The contributions made by Helene Hudson to oncology nursing have had far-reaching effects on cancer care in Canada. It is clear that her dedication to oncology has been an inspiration to nurses and has guided care of patients and families affected by cancer. Thank you to CANO for this honour.

\section{Abstract}

Research regarding experiences of nurses caring for family members with a cancer diagnosis is limited. To address this gap, a hermeneutic phenomenology approach was used to explore lived experiences of five nurses caring for family members living with advanced cancer. Their experiences were fraught with tensions and conflicts as they balanced the roles of nurse and caregiver. At the heart of their experiences was a sense of being caught in a web of conflicting expectations. Their struggles of expectations stemmed from anticipating the illness trajectory, expectations from family, expectations from other health professionals, and expectations from the nurse caregivers of themselves. Conflict between their professional and personal lives was most challenging. Implications of this care-giving situation are described.

At some point in their lives, most nurses will assume caregiving responsibilities for family members such as partners, aging parents and others who are ill. With the dramatic increase in cancer rates expected in the next few decades, many nurses will be caring for family members with cancer diagnoses. Cancer is a difficult disease with the potential to create an emotional, practical and existential crisis for the individual with the diagnosis and those directly involved in his or her care (Mills \& Aubeeluck, 2006). When it progresses to advanced disease, family caregivers often experience emotional and psychological stress. If the caregiver is a nurse, she/ he may find themselves entering a world that they previously have only witnessed through the patients and families they have known. Little is known about the experiences and perspectives of nurses who care for loved ones diagnosed with cancer. The purpose of this study was to explore nurses' lived experiences of caregiving when a

\section{About the authors}

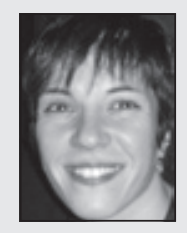

Lisa Cicchelli, RN, MN, Breast Health Nurse Coordinator, IWK Health Centre-Breast Health, Halifax, NS.

Office: (902) 470-2747; Fax (902) 470-6696. Email: lisa.cicchelli@iwk.nshealth.ca

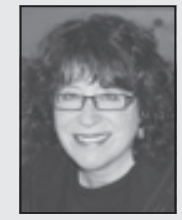

Deborah McLeod, RN, PhD, QEII Health Sciences Centre, Cancer Care Program, Halifax, NS.

Office: (902) 473-2964; Fax (902) 473-2965; Email: deborahl.mcleod@cdha.nshealth.ca

family member is diagnosed with an advanced cancer. For the purposes of this study, the term advanced cancer refers to cancer that is at a progressive, metastatic or terminal stage.

\section{Background}

The effect of a cancer diagnosis on family members has been well-described in the literature (Björk, Wiebe \& Hallström, 2005; Eldredge et al., 2006; Osse, Vernooij-Dassen, Schade, \& Grol, 2006; Schumacher et al., 2006; Scott, Hwang, \& Rogers, 2006). Strain resulting from caregiving has been shown to lead to high levels of distress, such as depression, anger, anxiety, relationship disruption, and isolation (Koerner \& Kenyon, 2007; Perreault et al., 2004).

In Canada, there is an increasing demand for resources to care for the elderly and chronically ill (Caron \& Bower, 2003; Nevidjon, 2004; O’Brien-Pallas et al., 2003). A significant source of care for the ill and the elderly are family members. The profile of a typical caregiver is a woman aged 46, married, employed full-time, and spending 18 hours a week on caregiving (Lockwood, 2003). There is increasing awareness that many illnesses like cancer have become a family issue instead of being solely the concern of the individual with the disease (Caron \& Bowers, 2003; Dumont et al., 2006).

Some studies identify that the tasks and burdens of nurses associated with family caregiving are often numerous, varied and frequently changing across the course of a family member's illness, as it often is for caregivers more generally (Mills \& Aubeeluck, 2006). However, the potential differences between lay caregivers and nurses who are caregivers for their own family members are poorly understood. A more thorough understanding of the issues might reveal possibilities for supporting nurses in their caregiving roles, including workplace accommodations. Researchers and organizations have identified that the health care system is beginning to struggle with the challenge of addressing the impact of the aging population of nurses (Andrews, Manthorpe, \& Watson, 2005; CRNNS, 2006; Villeneuve \& MacDonald, 2006). However, studies to date have done little to specifically explore and address the issue of aging nurses involved in caregiving roles in their own families.

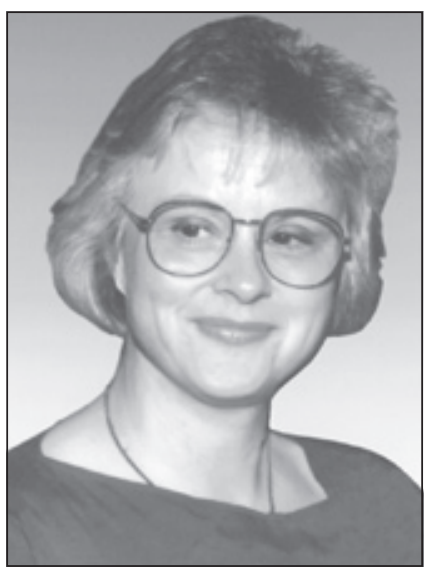

Helene Hudson-1945-1993

\section{Methods}

This study was guided by hermeneutic phenomenology, an approach that attends to the human world, as it is experienced. Hermeneutic phenomenology is oriented to discovering the meaning of a particular phenomenon as an essentially human experience in the social, cultural and political context in which the experiences occur (van Manen, 1997).

Ethics approval was obtained from the local Research Ethics Board. Study participants were practising nurses in Nova Scotia who were either cur- 
rently providing some aspect of care to an adult family member with an advanced cancer, or had cared for a family member in the past who had died from a cancer diagnosis. Caregivers were not required to live in the same household as the ill family member, but were required to live in close geographic proximity, provide some aspect of emotional or physical care and were actively involved in helping to make treatment decisions. In order to maintain confidentiality, participant aliases were used throughout the duration of the study. The study sample consisted of five registered female nurses who, except for one, were 45 years of age or older. Most cared for either ill parents or in-laws, and one nurse cared for her aunt. The family members were diagnosed with different types of cancer-pancreatic, lymphoma, colon, lung and breast cancer.

The primary method of data collection for the study was semi-structured interviews. The interviews provided participants with the opportunity to talk about their experience of caregiving. The interviews were audio-taped, transcribed verbatim and audited for accuracy. The transcripts were then read multiple times and interpretive memos were written. Thematic patterns were identified.

\section{Findings: Caught in the middle}

The overall theme identified was of being caught in the middle. The nurses described continually negotiating expectations and boundaries of two roles - that of being a family member and of being a nurse. Within the overall theme, there were several subthemes. These included balancing professional and personal relationships, holding privileged information, experiencing the health care system from the perspective of a care recipient, witnessing the illness and decision-making for their family member.

\section{Expectations of care: Balancing professional and personal boundaries}

Caregiving was described by the nurse participants to be a frustrating experience at times. While they often described feeling confident and comfortable providing physical care, they sometimes felt inadequate and helpless in the caregiving role. This was particularly the case when they witnessed emotional or spiritual suffering in their family member. One respondent described struggling with her expectation that she should be able to help her mother with her emotional needs and be able to "establish therapeutic communication".

I think the most difficult experience of caring for her was the psychological issues. As a nurse I [knew] that people go through all these stages of dying. You go through the denial, anger, frustration. I wanted to be able to talk to her about those issues. But, she wouldn't talk to me. I was thinking what am I doing wrong? I knew she was scared. I wanted to make it a nice death, a death with dignity, a death where she could talk about her feelings and we could get her help. It just never happened. If I could change anything, that is what I would change.

Another participant who cared for her father described her experience in this regard.

That was really frustrating for me, because there wasn't anything that I could do to help him. I didn't know how he was feeling. You bathe someone and it is over. It may be physically challenging. It can be hard. But the emotional is ongoing, so you are always working on it.

None of the participants, who reported these struggles, seemed to question the appropriateness of trying to address emotional needs of a family member from a position as a professional or saw the conflict of the dual roles-that of loved one and health professional-in which they were caught. These dual roles created conflicting expectations and obligations that were difficult to manage in the midst of their own emotions and grief.

\section{Expectations of care: Holding privileged information}

Nurses have professional knowledge that aids in understanding a variety of illnesses and the care and treatments required. They are often viewed by family members as information sources who may assist the family to negotiate illness. The nurses in this study had varying degrees of familiarity with oncology but, at times, did not have as much knowledge as their family members expected them to have. At other times the knowledge the nurse held increased her fear and stress.

I don't know if I didn't have the nursing background if I would have been as scared. At one hand, it was great to have all the knowledge, but on the other hand, I did have this background seeing and knowing what could be potentially going on. Now, looking back, I think it was helpful, but I think it just made things a little bit more stressful knowing that it [death] could happen.

Each of the nurses in this study held different kinds of knowledge about their loved ones' situation. At times this was seen as a strength helping them to better understand the situation and provide support to family members. At other times this was a source of stress, particularly when they held "privileged" information that was shared with them by other health care professionals because they were nurses, information that was not shared with the family generally. At these times, some did not know how or when to relay the information to their family members.

\section{Experiencing the health care system} from the perspective of a care recipient

Being on the receiving end of care was challenging for some participants. For some, this was their first significant experience of being a recipient of care. Their experiences as family members often clashed with their expectations of health care providers and systems, at times creating tense situations. One nurse commented on this.

Palliative care did a home assessment. I had mentioned to them that I felt that she [mother] was depressed. They put her on a small amount of medication, but it was not doing anything. I told them that she was depressed. I thought they would change the medication when they came and talked to her. They asked, "Are you depressed?" and she said "No" and that was it. Is that how we do a psychological assessment to find depression? [They] don't live with her everyday and I was kind of upset that they didn't listen to me.

One participant described how she felt about how she was treated as a family member.

[I felt] angry. The whole idea of treating the patient isn't just the patient. It has to be the family too. I don't think they did a good job. They zeroed in on my mother and they didn't care about anybody else... I thought it was all physical [care]. There was no psychological component.

The expectations of care were not always met and when that was the case, the nurses often managed the gap by using their professional connections. "I knew exactly who to call... We had Home Care in, VON came in and there was a third person."

She went on to talk about being angry about how health professionals shared information with each other.

It was getting tiring... I was becoming very angry. I kept thinking there is no excuse for three people to ask the same set of 
questions on the same day. It just didn't make any rational sense. How could you do an assessment and not be able to share that?

\section{Witnessing the illness}

Some of the nurses, like any family members, were distressed by witnessing their loved one's illness. While all the nurses had seen patients decline from illness and die, it was obviously a much different experience when it was a loved one. They tried hard to help, believing they should be able to alleviate the suffering.

I [gave] her opportunities to discuss her feelings and fear of dying. She wouldn't discuss any feelings. [I watched] her suffer and stare at a wall. [It was] difficult to watch. She would come to the table, eat two spoonfuls, say nothing and then leave. It is hard to watch somebody go downhill and not know how they are feeling... I couldn't [stand to] see her suffer. [Putting] her in the bathtub, taking her clothes off, seeing her skeleton. Nothing there but skin and bones. That was hard.

\section{Decision-making for the family member}

Study participants were often required to help in making difficult decisions about things such as cancer treatments. One nurse described her personal struggle with her family member's decision to undergo chemotherapy treatment. The nurse's past experience working in palliative care shaped her opinion of chemotherapy. She admitted to initially disagreeing with the decision, but later acknowledged that the chemotherapy had been beneficial to her loved one.

I [was there to] help in the decision-making for one thing... and even with the first chemo, they were a bit iffy at first if she should have anything other than radiation for the bone mets and pain control... I really wrestled with it myself because I see so many patients so sick with chemo and getting chemo probably that they shouldn't be getting... it is really iffy if it is causing more problems or not. And we see that, we see that on the other end, I certainly see benefit too, but certainly I didn't want to put her through anything more than what she had been through... So I really, really wrestled with that. But she just took it amazingly, no bad side effects and within days she started to feel better... It went from no hope to full circle of hope.

\section{Discussion}

This study was designed to explore the lived experiences of nurses caring for a family member experiencing cancer. The study findings offer some insight into the issues and tensions nurses face as they balance the dual role of nurse and family member. While the nurses in the study were found to share various caregiving experiences similar to other caregivers, they also reported unique experiences related to being a nurse.

Caregiving expectations may involve an anticipation of occurrences or predictions about illness trajectory, roles that caregivers and patients assume, and the behaviour of patients and their family members. The nurses in this study had particular expectations of themselves, as caregivers, because of their professional nursing knowledge. They often anticipated next phases of the illness and tried to prepare themselves and their family for them. Mills and Aubeeluck (2006) also found that nurses in their study frequently spoke about "jumping ahead" and anticipating next stages of the illness because they already knew what to expect.

Being confronted with the need to provide care and powerful family expectations, the nurses in this study all took on caregiving roles readily. They described long hours, difficult conversations with family, extensive travel to be with loved ones and the related stress and strain. Their experiences were physically and emotionally draining, much the same as is described by other caregivers (Mills \& Aubeeluck, 2006; Scott et al., 2006). The participants took on the demanding caregiving role, while largely maintaining their work responsibilities. They described feeling an obligation to care due to the fact that they were nurses and may have suffered an additional caregiver burden as a result (WardGriffin et al., 2004).

Despite expressing stress over the expectations of them by family members, the nurses in this study never discussed, challenged or clarified the expectations. Rather, they took on the caregiving role without discussion of what was being asked of them. None of the nurses seemed to consider how the caregiver role might affect their relationship with their loved one. Clarifying expectations early in the disease process might be one way for nurses to manage such a stressful situation. Being clear about expectations and communicating them might create opportunities for mutual support and ongoing clear communication among family members. In this case, the burden of caregiving might be shared rather than the assumption being made that because of her professional status, caregiving was "easy" or "natural".

Studies have shown that nurse carers are strongly influenced by norms and expectations to provide care, often without recognition of their own needs (Mills \& Aubeeluck, 2006). According to Grande et al. (2009), the norms of caregiving are usually embedded in social and cultural contexts and are further reinforced by interactions with family, the ill relative and the internalized feeling of the carers themselves. The nurses in this study took on the role by virtue of their familial relationship and social situation, but their nursing background situated them and was a strong force that shaped their caregiving experience.

The caregiving role for the nurses was not always described as a negative experience. The nurses generally felt satisfied in caring for their family members and were largely pleased with their involvement. The nurses were proud of their ability to care and meet challenges; this provided them with a sense of meaning and purpose. Their nursing knowledge helped them to provide comfort to their loved ones. Their experience caring for their family member also influenced and shaped their own professional practice.

For many people, providing care to an adult family member with cancer is not a role typically anticipated or chosen and is often assumed with little notice or training. This differs in the case of nurses, who have education and training and can foresee the nature of disease and the intensity of caregiving work. In the participants' minds, and in the minds of their families, it was perhaps an obvious choice that they play a large role in providing care to their family member, a choice that is certainly less obvious when there is no nurse or health care professional in the family.

The boundaries between professional and personal caregiving were blurred and demanded continuous negotiation for the nurses in this study. The most challenging aspect of this was in relation to holding privileged information, whether through education or private sharing of information from other health professionals because they were nurses. Since they were able to interpret the situation as it unfolded, the nurses typically had information much earlier than any of their family members. They struggled with how much information to divulge, how to divulge it and when to do so.

Caregivers, including health care professionals, often go unnoticed in health care systems (Mills \& Aubeeluck, 2006). The nurses in the study expressed their expectation that they should receive a certain amount of emotional and supportive care by other health care professionals caring for the ill family member. However, some shared disappointment in how they were treated. Some commented that they considered themselves a patient in the situation, but felt ignored or unattended to during the experience. Some of the nurses did not want to appear critical of their professional 
colleagues, which may have prevented them from voicing their dissatisfaction and the emotional conflict to the health professionals involved with their family member.

The nurses in this study chose to continue working through most of the caregiving experience and most found the experience to be largely positive and rewarding. Studies have shown that caregivers providing care for family diagnosed with cancer often benefit from being employed (Kim et al., 2006; Lefaiver et al., 2009). Working while caring for family members may offer respite for caregivers, provide opportunities to refresh psychological resources and concentrate on something other than their responsibilities at home. One could conclude that the decision of the nurses to continue working contributed to their satisfaction with their involvement with their family members.

Over the past 10 years, more attention has been paid to the work of nurses and the need to address work-life issues, such as health and wellness and flexibility of schedules. The illness of a family member can add to the work-life tensions, as nurses try to juggle work and family caregiving demands. The nurse participants found it helpful when they could take time away from work to be with family. They also commented often on the fact that

\section{References}

Andrews, J., Manthorpe, J., \& Watson, R. (2005). Employment transitions for older nurses: A qualitative study. Journal of Advanced Nursing, 51(3), 298-306. doi:10.1111/ j.1365-2648.2005.03501.x

Björk, M., Wiebe, T., \& Hallström, I. (2005). Striving to survive: Families lived experiences when a child id diagnosed with cancer. Journal of Pediatric Oncology Nursing, 22(5), 265-275. doi:10.117 7/1043454205279303

Caron, D., \& Bowers, B.J. (2003). Deciding whether to continue, share or relinquish caregiving: Caregiving views. Qualitative Health Research, 13(9), 1252-1271. doi:10.1177/1049732303257236

College of Registered Nurses of Nova Scotia (CRNNS). (2006). Retirement and Retention of Late Career Nurses in Nova Scotia. Halifax, Canada. Author.

Dumont, S., Turgeon, J., Allard, P., Gagnon, P., Charbonneau, C., \& Vezina, l. (2006). Caring for a loved one with advanced cancer: Determinants of psychological distress in family caregivers. Journal of Palliative Medicine, 9(4), 912-921. doi:10.1089/jpm.2006.9.912

Eldredge, D.H., Nail, L., Maziarz, R.T. Hansen, L.K., Ewing, D., \& Archbold, P.G. (2006). Explaining family caregiving role strain following autologous blood and marrow transplantation. Journal of Psychological Oncology, 24(3), 53-74. doi:10.1300/J077v24n03_03

Grande, G., Stajduhar, K., Aoun, S., Toye, C., Funk, L., Addington-Hall, J., Payne, S., \& Todd, C. (2009). Supporting lay carers in end of life care: Current gaps and future priorities. Palliative Medicine, 23, 339-344. doi:10.1177/0269216309104875

Kim, Y., Baker, F., Spillers, R.L., \& Wellisch, D.K. (2006). Psychological adjustment of cancer caregivers with multiple roles. Psychooncology, 15, 795-806. doi:10.1002/pon.1013

Koerner, S.S., \& Kenyon, D.B. (2007). Understanding "good days" and "bad days": Emotional and physical reactivity among caregivers for elder relatives. Family Relations, 56(1), 1-11. doi:10.1111/ j.1741-3729.2007.00435.x

Lefaiver, C.A., Keough, V., Letizia, M., \& Lanuza, D.M. (2009). Quality of life in caregivers providing care for lung transplant candidates. Progress in Transplantation, 19(2), 142-52. flexibility in the workplace was beneficial in their ability to care for the ill family members. Research supports the need for flexibility in the workplace in order to balance work and home life responsibilities (Andrews et al., 2005; CRNNS, 2006; Scott et al., 2006). The flexibility could include things like scheduling changes, assignment changes and hours of work. This need is even more important as nurses age and find themselves caring for ill, aging family members.

\section{Conclusion}

Nurses who provide family caregiving are in a unique situation, in that they have knowledge of illness and health care resources and a degree of confidence in caregiving. The nurses articulated some caregiving issues that are commonly identified by other caregivers. However, there were also issues raised such as expectations of care, divulgence of information and the blurring of professional and personal boundaries that appear to be unique to nurses and that can cause additional burden. The findings of this study suggest that a broader understanding of dual caregiving by nurses might be helpful in negotiating the complexities involved in caring for their own family members.

Lockwood, N.R. (2003). The reality of the impact of older workers and eldercare in the workplace. HR Magazine, 48(12), 1-11.

Mills, J., \& Aubeeluck, A. (2006). Nurses' experiences of caring for their own family members. British Journal of Nursing, 15(3), 160165.

Nevidjon, B. (2004). Managing from the middle: Integrating midlife challenges of children, elder parents, and career. Clinical Journal of Oncology Nursing, 8(1), 72-75. doi:10.1188/04. CJON.72-75

O’Brien-Pallas, L., Alksnis, C., \& Wang, S. (2003). Bringing the Future into focus: Projecting RN Retirement in Canada. Ottawa: Canadian Institute for Health Information.

Osse, B.H., Vernooij-Dassen, M.J., Schade, E.., \& Grol, R.P. (2006). Problems experienced by informal caregivers of cancer patients and their needs for support. Cancer Nursing, 29(5), 378-388.

Perreault, A., Fothergill-Bourbonnais, F., \& Fiset, V. (2004). The experience of family members caring for a dying loved one. International Journal of Palliative Nursing, 10(3), 133-143.

Schumacher, K.L., Beidler, S.M., Beeber, A.S., \& Gambino, P. (2006). A transactional model of cancer family caregiving skill. Advances in Nursing Science, 29(3), 271-286.

Scott, L.D., Hwang, W.T., \& Rogers, A.E. (2006). The impact of multiple caregiving roles on fatigue, stress, and work performance among hospital staff nurses. Journal of Nursing Administration, 36(2), 86-95.

van Manen, M. (1997). Researching Lived Experience. London: University of Western Ontario.

Villeneuve, M., \& MacDonald, J. (2006). Towards 2020: Visions of Nursing. Ottawa: Canadian Nurses Association.

Ward-Griffin, C. (2004). Nurses as caregivers of elderly relatives: Negotiating personal and professional boundaries. Canadian Journal of Nursing Research, 36(1), 92-114.

Williams, L.A. (2007). Whatever it takes: Informal caregiving dynamics in blood and marrow transplantation. Oncology Nursing Forum.,34(2), 379-387. doi:10.1188/07.ONF.379-387 